\title{
Brand Slogan of Region: Valuable Aspect of Place Marketing
}

\author{
Vera A. Mityagina, ${ }^{1, *}$, and Irina G. Sidorova ${ }^{2}$ \\ ${ }^{1}$ Volgograd State University, Volgograd, Russia \\ ${ }^{2}$ Volgograd State Medical University, Volgograd, Russia
}

\begin{abstract}
The purpose of the present paper is to provide a linguistic analysis of current regional brand slogans. This paper argues that the place branding process should be examined not only in the context of destination marketing thought, but as a value-shaped approach. This study attempts to evaluate the slogans of tourism destination by means of communicative and pragmatic characteristics expressed by them: strong sides of the community, perceptiveness, self-confidence and confidence in future. The present research illustrates how linguo-cultural values are explicated in English, German and Russian branding slogans in accordance with the specific objectives motivated by regional features (natural resources, historical events, sights, products and services).
\end{abstract}

\section{Introduction}

Nowadays place marketing aimed both at attracting investments and specialists and tourism development is mostly implemented through effective branding of regions, cities, their most interesting sights and events.

In the paradigm of economic studies, the thought of this phenomenon as an interaction between consumers (citizens) and products (cities, regions, and countries) [1] is considered to be widely spread. 'Place branding' is taken as a help to countries / cities / regions for promoting themselves "from being mere suppliers of goods without a well-defined brand to owners of their own brands and branded destinations" [2].

Several researchers claim that the purpose of regional brands creation is a steady increase of investment and tourist and recreational appeal of a relevant geographical unit; this process should preferably result in acceleration of socio-economic development in this region [3].

However, in linguistics there are not many studies of discursive practices of regional branding. This study presents an analysis of current city slogans, cases of their positive and negative usage. Our attention is focused on forming a complex overview about what linguistic means provide for the efficiency of regional branding, what texts should be used for effective slogans (or mottos), and what values reflect the positive sides of a city or region.

According to the study by researcher I.S. Vazhenina, along with utilitarian consciousness of branding, the natural value of territorial brand as "the complex of timeless values that reflect the peculiarity, unique and original consumer properties of a certain territory and community" [4] has become evident.

This approach seems to be quite efficient because it allows us to make a multi-aspect overview of what makes regional branding effective.

\section{Background}

'Regional Branding' and its implementing in the different spheres of human activity are current and urgent topics in modern research. It can be explained by that fact that there are a lot of destinations which are unique but unpopular among not only the international tourists, but among domestic tourists and residents. So, we consider that the effectiveness of establishing and promoting destination uniqueness may be achieved by means of compatible value-oriented regional features which should be reflected in slogans (or mottos).

The process of branding is an object of sociopsychological study by researcher Yu.Yu. Brovkina. In her study, Thesis of a Doctor of Psychology, she defines the term 'brand-communication' as "a specific process of interactions resulting in the changes in motivation, arrangement, behavior, and activity of people and resulting in creation of a conventional brand image as a social object... The brand discourse is a motivation discourse" [5]. Therefore, this approach is significant for understanding the pragmatics of interactions in line with realized intentions. Yu.Yu. Brovkina emphasizes the pragmatic hypothesis of her study by offering a typology for participation in brand-communication, and based on her studies the language logistics of this process may be characterized as dialectic antithesis and a factor for the synthesis of scientific thought.

The philosophical thought of the phenomenon of branding is also taken in communicative aspect: the researcher S.A. Shusharin draws attention to the role of a brand by way of "conversation subject, the topic of discussion on forums, in social networks and etc." [6]. The structure of brand discourse and its imaging is presented in the studies of PR-discourse by researchers

* Corresponding author: mityagina@ volsu.ru 
O.F. Rusakova and V.M. Rusakov [7]. The marketing approach to development of national brand is presented in the study by N. Galí, R. Camprubí, and J.A. Donaire "Analysing tourism slogans in top tourism destinations" in which the researchers consider a tourism destination slogan as "an important tool in the development of the national brand", and they assume that "slogans tend to be very simple and have an exclusive appeal, which comes from emphasizing the affective component in the message" [8]. A. Zbuchea in her study "Territorial Marketing Based on Cultural Heritage" asserts that heritage is an important part of modern society and "in most cases, heritage promotion is coordinated by the heritage management and/or by those designing the territorial marketing strategy" [9].

\section{Analysis of Regional Branding}

Regional branding is the process of popularizing the objects of cultural and historic value both on the local and international levels. We come along with the researchers A.A. Gureeva, T.S. Sidorovich and A.A. Novozhilova that "the interest focus of linguists conducting their research of travel discourse has recently started shifting to the analyses of image texts and texts aimed at territorial (place) branding", and we acknowledge that in this way "proper linguistic assistance of branding is an important component promoting positive character of regions and attracting more tourists into these regions" [10].

We certainly agree with the known opinion that to make a territory attractive to potential tourists this city destination should offer sights (historical and contemporary objects, natural landscapes), products and services (unique and related to the destination), events (cultural, business, and sporting events, festivals, etc.), or this one could also be based on a relation to a historical figure, such as a famous artist or writer, who was born in, lived in or visited the territory.

Special attention should be given to brand identity which means its uniqueness and the defining characteristics of its nature [11]. According to the study of K. Margarisová and L. Vokáčová, brand identity includes brand personality, cultural values, values and relationships that the brand represents, the typical reflected consumer, self-perception, i.e. "self-image expression" of the consumer of the brand; the sources of brand identity can include the typical products, name, visual elements, geographical and historical roots, the creator and propagation (communication) of the brand [11].

However, it is difficult to agree that natural values associate with the particular destination; social research devoted to the study of formation factors of a city brand pays great attention to the fact of their being not only and not so much "memorable logos and costly advertising", as "its spiritual foundation, i.e. the essence of city..." [12]. Researcher E.A. Gorbataya makes a point that the critical factor in city brand formation is preserving cultural foundation of territories, values, styles, a remarkable atmosphere of urban environment, and therefore, its symbols [12].
Basing on the analysis of categorical refusal to replace the symbol of Volgograd - "The Motherland Calls" sculpture with the symbol of Light Tower, the researchers V.A. Paramonova and A.S. Abdusheva have come to conclusion of obligatory compliance of 'place branding' with the system of modal values shaped in the society on the whole, and on particular territory, especially [13].

Metaphorical emphasis of a woman sculpture presenting the figure of 'mother' with a focus on corporeal culture studies [14] taking place in the sphere of territorial self-awareness of local residents unites the brave feats of mothers of the Defenders of Stalingrad with the city's history.

The reviews of researcher T.Yu. Bystrova seem to be controversial: on the one hand, she considers the brand to be an economical category dependent on the budget, on the economic situation [15], but on the other hand, she defines the brand as "non-material value constituents supplementing attractiveness for the territory, product or the service in the customers' minds" [15]. The researcher insists that the values stated and expressed by the brand should be original and consequently checked out and confirmed; she points to the necessity of rejecting mythologization "being still actively accepted on the regional level nowadays" as well as the necessity of "making them available for acquisition, feeling and interpretation; achieving the particular single meaning, name recognition in their presentation" [15].

These conclusions and recommendations of the colleagues in humanitarian understanding of the axiology of branding as a communicative process are in need of concrete definition that may be proposed by research approaches of discursive investigatory paradigm of anthropological linguistics. That is, language as a sign system, in the opinion of V.I. Karasik, reveals unlimited possibilities of generating and attaching meanings; moreover, its substantive universe in cultural meaning is structured in the form of value-based worldview determining our thinking of reality [16]. A brand, according to his significant definition, is a trade mark of the combination of emotional and estimating stereotypes towards the intended product [17].

Extrapolation of the understanding of the definition of 'brand' to the analysis of the discursive space of territory marketing objectifies the necessity of working out the meaning of a brand as a carrier of code information of major regional values.

It seems worthwhile to draw attention to the following facts. Successful city and region brands are always oriented at not only tourists but primarily at the new potential residents, investors, qualified specialists, and as A.A. Gureeva suggests, "a positive image of a foreign city / region depends on efficient communication within intercultural travel discourse" [10]. And moreover, city branding cannot be efficient and beneficial without utilizing verbal approaches to creating a tourist-attractive image of a city or region.

Besides, the tasks of territorial branding are to develop tourist-attractive places and to transform the existing ones into attractive places for visitors. We assume that territory places marketing is also aimed at people residing here who should know that they live in a very interesting, 
significant and perspective place which is developing in line with basic, humanistic and their own unique values.

To test our hypotheses, we suppose that it is necessary to pay attention to the experience of the countries that are included into the Top-List of 10 most visited countries [18]. We should mention that Russia is stably included into this list. However, the countries included into this group are not restricted by branding of particular objects; moreover, they implement region branding, and in the case of Germany - emphasize the marketing of the Federal States.

For a detailed analysis let us pay attention to the 'primary' brand components such as the name of region and its slogan. The study by V.A. Mityagina et al., devoted to analysis of texts of tourism branding, proposes that "the brand of the territory is an indicator of its recognizability, a tool for its presentation on the regional, country, or even world level" [19]. Taking this proposal into account we concluded that relevant nominative processes associated with German well-known abbreviation practically create logos that are successfully used in very different contexts. For example, these city's abbreviations are highly recognizable and efficient: $B B-$ Brandenburg, NI - Niedersachsen, SL - Saarland, BEBerlin, NRW - Nordrhein-Westfalen and etc. Hanseatic cities (Hansestädte) Bremen and Hamburg, which are the Federal States of Germany, have kept their historical official name, as number of other cities of the Hanseatic Union, in these abbreviations: $H B, H H$.

Analyzing the abbreviation used for branding Russian cities and regions, however, we should draw not very beneficial analogy for the Volgograd Oblast: the abbreviation ' $V O$ ' (' $B O$ ' in Russian) has been recognizable only in the abbreviation ' $A V O$ ' (' $A B O$ ' in Russian) - 'the Administration of the Volgograd Oblast' and utilized in extremely limited borders of organizational business communication.

Although the slogans of the Federal States of Germany were created quite recently, their formation and sometimes changing, as well as survey data demonstrated search for a happy expression of something valuable and meaningful and also significant for the positioning of the region and its residents [20].

We should assume that the most successful slogans with more than a half of approval comments are the slogans of four Federal States of Germany - Schleswig Holstein, Thuringia, Saarland and Baden-Wuerttemberg. A study of these slogans showed the following facts:

1) Schleswig Holstein is presented by the regional marketing slogan 'Der echte Norden'/ 'Germany's True North' which seems as a serious and understandable representation. We suppose that this slogan reflects both natural resources, and human ones of the Federal States whose achievements are the results of overcoming the historic events.

2) Baden-Wuerttemberg is introduced by a very interesting contra positioning approach of this effective and popular geographic-oriented name of the Federal State to the previous slogan of 'Wir sind Süden' that means 'We are the South'. This nomination deprived of evaluating component was in high favour with less $20 \%$ residents, and the current and relevant slogan is 'Wir können alles - Außer Hochdeutsch' / 'We can do anything, except speak standard German'. This motto explicates both the potential, pride and self-irony of Germans who actually speak a complicated dialect. By the way, this slogan is the leader of the survey.

3) The slogan of Thuringia 'Hier hat Zukunft Tradition'/ 'There are the traditions of the future' is considered to be a very good, understandable and strong by the surveyed Germans.

4) Saarland, the smallest federal state of the Republic of Germany, is shown by the slogan 'Großes entsteht immer im Kleinen' / 'Great things will always arise from small ones'.

Apparently there are formulations which are quite neutral, not presenting tendential commitment to socio and cultural values, so the following slogans are in the middle of the slogan popularity's scale of the federal states of the Republic of Germany:

- 'Niedersachsen. Klar' /It's Lower Saxony. Of course';

- 'Weil starke Marken nicht viele Worte brauchen. Niedersachsen' / 'A strong brand needn't be presented. Lower Saxony';

- 'Wir machen 's einfach' / 'We simply do it';

- 'So geht Sächsisch' / 'It will be in the Lower Saxony's style';

- 'An Hessen führt kein Weg vorbei' / 'No one road goes through Hesse'.

It is obvious that such modest and simple mottos do not claim to great things and find support among the eastern Federal States of Germany, although these ones cause some puzzlementor their capability to express these priorities. For example, a slogan of Saxony-Anhalt 'Wir stehen früher auf' / 'We get up earlier' reflects the real fact that the residents start their day 9 minutes earlier than the average country; however, the doubtful value of this feature does not make the federal state attractive. The willingness to join enthusiasts getting up earliest of all in the country hardly ever counts with tourists as potential new residents of the region.

Adherence to the values and ideals of the Western civilization, the processes of globalization and integration are clearly expressed in the slogans of Berlin and North Rhine-Westphalia: 'Be Berlin', 'Germany at its best'. These key slogans of the Federal States of Germany are given in English for a reason; they are in high favour with residents. Therefore, the slogan 'The place to be' was launched in Berlin in 2008 with delivering 1.358.205 letters to Berliners that started to create an attractive image of Berlin on regional, national and international levels (https://www.sei.berlin.de/).

We should mention that this motto developed in German slogan of the federal state Mecklenburg-Western Pomerania (in German: Mecklenburg Vorpommern) 'Land zum Leben/ The place for life' evolved from another one ' $M V$ tut gut) $M V$ (Mecklenburg Vorpommern) does you well' which used to be more popular. We cannot help noting that the marketing trademark of this region was a beach basket as a symbol of comfortable recreation, and, of course, the most brilliant idea of the federal state branding was the photos of the G8 leaders in baskets on the Heiligendamm beach 
in 2007. The slogan 'Best of Northern Germany' in English which recently became important in global branding was added to the current slogans of this federal state.

We emphasize that the slogans of German states came about on different occasions and correspond to a Hollywood idea based on simple and available form, so the value component becomes very simple and singlevalued: 'Das Autoland Deutschland', 'Deutschland Land der Ideen'.

These slogans need not be translated to those who do not speak German; these brand slogans reflect not only the values of the German linguo-ethnosociety, but positive stereotypes about Germany: the country of autos, progress and perspective ideas.

European and American slogans are also examples of creating the qualitative digital brand of a city/ region/ country. The slogan of worldwide famous downtown of the city Las Vegas 'DOWNTOWN LAS VEGAS, NV 'Every City Has a Soul' gives the uniqueness and charm to this destination, and simultaneously reflects the essence of this part of the city attracting tourists with famous gaming pavilions and casinos and fashionable hotels.

The slogan of the magnificent ancient city of Scotland and nowadays its capital, Edinburg 'Inspiring capital' is also readily comprehensible and recognizable to tourists. The city will inspire not only with its historic surroundings and cultural patterns, but modern urban atmosphere in which you can go from museums and galleries to pubs, clubs or restaurants with a view of the harbour.

At the same time one of the world-famous cities Manchester located in the north-western part of England, the 9th greatest city in Great Britain, with 2.2 million metropolitan population and a major cultural, industrial, financial, transport and educational center of the country and the home to "Manchester United FC" football club attracts tourists with the unequivocal slogan 'Uniquely Manchester!'

However, in the context of the first faltering attempts at territory marketing in Russian, we should emphasize that the items 'brand', 'logo', 'slogan' as well as 'territory marketing', 'brand management' and 'branding' are used quite often as synonyms, so, obviously, it is the illustration of immaturity of brand discourse. Not numerous slogans of the Russian regions are far from expressing identical regional socio-cultural values:

- Kazan: 'The third Capital of Russia';

- Ulyanovsk: 'Aviation Capital of Russia',

- Novosibirsk: 'The Capital of Siberia';

- Nizhny Novgorod: 'The Capital of the Volga region';

- Dobryanka: 'The Capital of Kindness' [21].

It is interesting to note that the previous tourist brand of Kazan created immediately after the events devoted to the 1000-th anniversary of Kazan, was "Kazan is where Europe Meets Asia". Its logo represented word KAZAN written in Latin, which was completed with "eastern ornament and a stylized image of a Zilant dragon". However, in 2009 the capital of Tatarstan took out a patent for title "Third Capital of Russia" and a new territorial brand was created with slogan "Kazan is Russia's Third Capital'. [3].

We are sure that all of the best in Russia is related to the Russian city centers, and it is clear that branding these territories reflects the valuable capability to be the center of anything. For example, the slogan of Nenets Autonomous Okrug 'The North European pantry in Russia' suggests a claim to exclusiveness. Nowadays the brand name for Moscow, the capital of Russia, is being developed according to the strategy of priority, domination and exclusivity - 'The capital is the international and cultural center'.

The refusal to search for the means of linguo-cultural values corresponding to collective consciousness and collective unconsciousness or regional society, results in practically caricature decisions: a foreign agency created a new logo for St. Petersburg in the form of a lion head and gave the city the slogan of 'No bears! Just beauty!'. This variant fell through without any support. Being the part of the brand of St. Petersburg the odious status 'The capital of the Russian Culture' has become an idiomatic escape from negative stereotypes which are often shown in branding slogans.

It is worthwhile to say that the European experience of place marketing is more successful. Considering the importance of effective city branding the European Committee of the Regions holds the European Week each year where the organisers discuss and accept significant decisions how to make and facilitate regional brands. According to the last meeting in 2017, the European Week was held under the overall slogan 'Regions and cities working for a better future', with the following three thematic priorities:

- Building resilient regions and cities;

- Regions and cities as change agents;

- Sharing knowledge to deliver results.

The results were complemented in the branding guidelines "The European Week of Regions and Cities 2017. Specific rules and applications in 2017" [22]. We are sure that such meetings should popularize, strengthen and facilitate the positioning strategies of effective place branding.

\section{Conclusion}

The present study showed that an effective branding slogan is a motto expressing strong sides of a community, perceptiveness, self-confidence and confidence in the future. Linguo-cultural values are explicated in the branding slogan in accordance with specific objectives motivated by the level of positioning of the destination: regional, national and/or global. Territory marketing relates to all aspects of branding as a communicative process, and the data of this linguistic study of the phenomenon of branding can encourage making some real-life economic decisions effective.

This research was conducted with the financial aid from the Russian Foundation for Basic Research (RFBR), the Administration of the Volgograd Region, Project No. 17-1434001 Regional Tourism as Factor of Discourse and 
Translation Technology Formation: Nominative and Communicative-Pragmatic Conventions of Branding Texts (Volga Lands in the History and Culture of Russia 2017 Regional Contest, Volgograd Region).

\section{References}

1. P. Kotler, C. Asplund, I. Rein, D. Haider, Marketing City Places. Attracting investments, industries, residents and visitors to cities, communities, regions and countries in Europe (Stockholm school of economics Publ., St Petersburg, 2005)

2. S. Anholt, Places: identity, image and reputation, (Palgrave Macmillan New York, 2009)

3. B.M. Eidelman, L.R. Fakhrutdinova, N.K. Gabdrakhmanov, A.M. Nayda, Academy of Marketing Studies Journal 20 (1), 39-44 (2016)

4. I.S. Vazhenina, Marketing in Russia and abroad 6, 82-98 (2006)

5. Yu.Yu. Brovkina, Social psychology of brandcommunication (Published thesis of a Doctor of Psychology, Moscow, 2009)

6. S.A. Shusharin, Communicative essence of brand in modern culture (Published thesis of a Candidate of Philosophy, Omsk, 2014)

7. O.F. Rusakova, V.M. Rusakov, PR-discourse: theoretical and methodological analysis (The Ural part of The Russian Academy of Sciences Publ., Ekaterinburg, 2011)

8. N. Galí, R. Camprubí, J.A. Donaire, Destination Marketing \& Management J. 6 (3), 243-251 (September 2017)

9. A. Zbuchea, Management\&Marketing XII, (2), 135151 (2014)

10. A.A. Gureeva, T.S. Sidorovich, A.A. Novozhilova, Advances in Social Science, Education and Humanities Research (ASSEHR), 97, 274-279 (2017)

11. K. Margarisová, L. Vokáčová, J. Acta Universitatis Agriculturae Et Silviculturae Mendelianae Brunensis 64 (6), 2059-2066 (2016)

12. E.A. Gorbataya, Branding of small and mediumsized cities in Russia: experience, problems and prospects, 45-49 (2012)

13. V.A. Paramonova, A.S. Abdusheva, City brand and its formation factors (on the example of Volgograd), Scientific J. "Izvestia VSTU” 6 (112), 88-91 (2013)

14. V.V. Zhura, Ju.V. Rudova, Zh.S. Martinson, Advances in Social Science, Education and Humanities Research (ASSEHR), 97, 342-347 (2017)

15. T.Yu. Bystrova, PR in a Changing World: The regional dimension: a collection of articles, 9, 85-95 (2011)

16. V.I. Karasik, Language matrix of culture (Paradigma Publ., Volgograd, 2012)
17. V.I. Karasik, Language crystallization of sense (Paradigma Publ., Volgograd, 2010)

18. Annaul Report of The World Tourism Orhanization $2016 \quad$ URL: http://www.eunwto.org/doi/pdf/10.18111/9789284418725 (date of access 15.04.2018)

19. V.A. Mityagina, E.Yu. Novikova, T.Yu. Makhortova, I.D. Volkova, Advances in Social Science, Education and Humanities Research (ASSEHR) 97, 320-325 (2017)

20. The slogans of the Federal States of Germany (The Handelsblatt, 10.03.2017) URL: http://www.handelsblatt.com/politik/deutschland/um frage-zu-werbespruechen-das-sind-die-beliebtestenslogans-der-deutschen-

bundeslaender/19493586.html (date of access 10.04.2018)

21. 15 regional brands of Russia (The Republic, 04.04.2013) URL: https://republic.ru/economics/10 territorialnykh bre ndov rossii-820899.xhtml (date of access 10.04.2018)

22. The European Week of Regions and Cities 2017 branding guidelines Specific rules and applications in 2017 URL: http://ec.europa.eu/regional_policy/regions-andcities/2017/doc/EURegionsWeek_2017 branding_g uidelines.pdf (date of access 20.04.2018) 